\title{
The ethics of medical involvement in torture: commentary
}

\author{
R M Hare University of Florida, USA
}

\section{Author's abstract}

Torture does need to be defined if we are to know exactly what we are seeking to ban; but no single definition will do, because there are many possible ones, and we may want to treat different practices that might be called torture differently. Compare the case of homicide; we do not want to punish manslaughter as severely as murder, and may not want to punish killing in self-defence at all. There are degrees of torture as of murder. Unclarities simply play into the hands of would-be torturers. Downie is unsuccessful in deriving the duty of doctors not to be involved in torture from an analysis of the word 'doctor'. It may be contrary to the role-duty of doctors to participate in torture; but there might be other duties which overrode this role-duty. The right approach is to ask what principles for the conduct of doctors have the highest acceptance-utility, or, as Kant might have equivalently put it, what the impartial furtherance of everyone's ends demands. This approach yields the result that torture (suitably defined) should be banned absolutely. It also yields prescriptions for the conduct of doctors where, in spite of them, torture is taking place.

Professor Downie's attempt, in his admirably clear and concise paper, to define 'torture' is the best that I have seen so far; but it is necessary to ask what purpose such definitions serve. Some may feel that verbal questions of this kind ought not to occupy our time. But whatever conclusions we reach will have to be expressed in words, and if the words have not been made clear, the conclusions will not be. For example, if we say that torture, or torture in certain specified circumstances, ought to be ruled out, it has to be clear precisely what we are saying should be ruled out. Downie says (page 135) 'From a practical point of view it does not really matter very much whether a practice is strictly torture or some other form of inhuman treatment; the point would be to get it stopped'. But we do need to be clear about what we want to get stopped.

\section{Key words}

Torture; medical skills; medical role.
However, it is probably fruitless, and may be positively confusing, to look for a single definition of 'torture'. There is a great variety of treatments which have been described as torture, ranging from the infliction of the most extreme physical pain for the most wicked purposes to the causing of quite mild mental suffering in pursuit of aims that are in themselves laudable. We may wish to condemn some of these practices and not others, and if we call them all by the same name we may get confused. At least we should try not to beg any substantial moral questions about the rightness or wrongness of certain practices by the way we decide to usef words.

It is worth looking at what has in most jurisdicen tions been done with the words 'murder' and 'homicide'. There are a great many different kinds of homicide (that is, of killing people), and there are even some of these that most people do not wish to condemn (killing in self-defence, for example). So we need at least to distinguish between culpable and non-culpable homicide. But even within the category of culpable homicide we make further distinctions (not the same in all jurisdictions). In English law we distinguish at least between murder and manslaughter (there is also a separate offence of killing by reckless driving and another of infanticide); and it is possible, as some jurisdictions do, to make further distinctions within the class of murders, in terms such as 'first-degree murder', 'second-degree murder', etc.

These distinctions have a purpose. We want to make the punishment, or the degree of condemnation, fit the crime, and do not think all crimes are equally heinous. If we had only one term, 'murder', for all these acts, it would not be easy to frame a clear law that would do this. Some homicides we do not want to condemn at all. So we divide homicides into categories and lay down different penalties, if any, for each of them. The definitions come after, and not before, we have decided how we wish to classify kinds of homicide, for the purpose of directing the courts to treat each category in a different way.

If we followed a similar procedure with torture, we should not start off with a very general, and inevitably vague and unclear, definition of 'torture'. 
Rather, we should look at all the various kinds of act that might be called torture, and then decide which of these kinds of acts we wished to condemn, and how severely. Only after that would we give names to the various kinds of act that we wished to condemn, or not condemn. We might end up with a lot of different 'degrees' of torture, and with some other terms (analogous to 'manslaughter') which did not imply so severe condemnation; and there would probably be some classes of acts that we called by names which did not imply condemnation at all.

Past failures to observe these precautions have resulted in the most muddled battles of words. One party calls what another party is doing 'torture'. The other party says that what it is doing is not (or not really) torture - as if it mattered what one calls it. The question rather is: Is this a kind of activity that ought to be banned? When we have decided that (which involves a close factual enquiry into the nature of the activity and its circumstances and aims), we can then go on to give it a name, and the name is unlikely to be simply 'torture'. There are certainly practices going on all over the world which ought to be condemned and if possible stopped. We make this more difficult if we use words in such a woolly way that those who are guilty of these practices can always say 'Yes, we use torture; but so do you when you make prisoners suffer as you do'. Since some suffering is in practice inseparable from imprisonment, this affords too easy an excuse to torturers. So, although I find Professor Downie's clarifications helpful, I do not think they take us far enough.

I now turn to my other main difficulty with his paper. He thinks that we can get guidance on how doctors should behave by examining the meaning of the word 'doctor'. I do not think he is successful in this. He distinguishes, rightly, between skill jobs, aim jobs and role jobs, and says that the doctor has all three. But it is possible to take on one or more of these jobs without taking on the rest. For example, someone might acquire the skill of a doctor, but not have the aim of healing. Or he (or she) might have both jobs, but not accept the role of doctor; he might want to heal people, but not acknowledge any duty to heal them. And if it is possible, the question must arise, ought a person to take them all on, or only some. This question can arise over a whole career, or on a particular occasion.

Downie says (page 137) 'It is not open for a doctor to say "I shall cease acting as a doctor while I engage in torture and then I shall resume the role later" '. But if he thought he had a duty to engage in torture (and we must not beg the question, as Downie seems to be trying to do, of whether he ever could have such a duty), then he might think that this duty required him to override, temporarily, the duties of his doctor-role, in order to perform the more pressing duty. It may be that there is not likely ever to be a duty to torture, but Downie has not shown that there is not.
A parallel may make this clear. It is clearly a role-duty of prison officers not to let prisoners escape. But if a prison officer thought that a certain prisoner had been wrongly convicted and was to be hanged for a crime he had never committed, he might think he ought to let the prisoner escape. He would of course be in breach of his role-duty if he did this; but he might think all the same that he had a moral duty which overrode this role-duty. The question could only be settled by a far-reaching examination of the circumstances of the case. If he let the prisoner escape, and was not detected as the person who did this, he might thereafter resume his duties as a prison officer.

It would be difficult for him to do it with a good conscience; but conscience is not always a reliable guide to duty. Conscience is the product of our upbringing, and gives good guidance in ordinary cases if the upbringing has been sound; but in extraordinary cases it may give the wrong answer. It went against Huckleberry Finn's conscience to help the slave to escape.

I am not saying that Downie ought, in his short paper, to have settled the entire question of whether torture is ever justified. But even though he was only asking, less ambitiously, whether, if torture ever is justified, a doctor could ever be right in getting involved in it, he has not settled even this question. For if torture were justified on a particular occasion, a doctor could not argue simply that, because he had the role of a doctor, he ought not to be involved in it. He might think that the duty to be involved in the (supposedly) justified torture overrode his role-duties as a doctor.

I do not think that either the question of whether torture is ever justified, or the question of whether doctors ought ever to be involved in it, can be settled without a much deeper examination of the 'methods of ethics', as Sidgwick called them. But having found fault with Downie's method, I ought perhaps to give some indication of how I would settle such questions. I am unusual in being both a Kantian and a utilitarian. Many philosophers think this is impossible, but they have not fully understood Kant. On the Kantian side, Downie rightly includes in his definition of torture (page 136) 'using that being as a means to an end to which the being has not consented'. This echoes Kant's dictum 'Act in such a way that you always treat humanity, whether in your own person or in the person of any other, never simply as a means, but always at the same time as an end' (1). Kant explains on the next page that others 'ought always at the same time to be rated as ends, that is, only as beings who must themselves be able to share in the end of the very same action'; and he goes on to say 'For the ends of a subject who is an end in himself must, if this conception is to have its full effect in me, be also, as far as possible, my ends' (2).

Take now the case of the terrorist who has put a bomb in a litter bin in a crowded place. Is it right to 
torture him to discover which bin? If we did that, we should of course not be treating his ends as our ends; for his ends no doubt include that of having the bomb explode. But what about the ends of all those who will be killed if the bomb explodes? If we treat their ends as our own ends, we shall perhaps think it right to torture the terrorist. And if there are a thousand of them and only one terrorist, we might think that we would do better, even according to Kant, to respect their ends rather than his, especially as his end is an immoral one (3). Thus it is possible to argue on Kantian lines for a utilitarian solution to such problems; for the utilitarian also would say that we should maximize preference-satisfaction in such a case, and obviously we shall do this if we use torture to discover the location of the bomb. (For further much needed discussion of the relation between Kantianism and utilitarianism see Hare 1993 (4).)

The same kind of reasoning can be used in the particular case of the doctor who is wondering whether he should get involved in the torture. I have argued that if he had a duty to get involved, this duty might override his role-duty as a doctor. Why then do we not only think of torture in itself as morally abhorrent, but think it even more abhorrent for doctors to be involved in it? We can see that it is quite right to think this, if we look at the actual circumstances of the world in which we live. Our moral principles have to be appropriate for everyday use in this actual world. That is why it is wrong to tailor them to extraordinary examples like the one just given.

Many people seem to fall victim to the elementary logical fallacy of thinking the following inference valid:

Torture is justified in some (conceivable) cases; Therefore it is justified in any case.

If this inference were valid, then we might be led to deny that torture was justified even in the most unusual cases, in order to avoid having to conclude that it was justified in more normal cases. But this is not only fallacious, but practically misleading. What doctors, and all the rest of us, need are sound principles for our conduct in the cases we are likely to encounter. It is hard to believe that the litter bin case would ever occur: that is, a case in which there was no way of locating the bomb except by torture. It is even more unbelievable that the skills of the doctor would be of much use in torturing the terrorist; torture is not all that difficult in such a case; a crude quick and effective means would be what was needed.

I have argued elsewhere (5) that the right rule for police to adopt would be to rule out torture absolutely. The reason is that once it is even contemplated, it will be used, and spread, and the end result will be much worse than the evils that torture was supposed to counter. This is consistent with admitting that cases are conceivable in which torture would be the right course; I gave a highly improbable example in the place cited. In the world as it is, it never will be the right course. Therefore policemen should not even contemplate it; and the same is even more true of doctors.

However, in regimes where, in spite of this, torture is practised by the police, difficult situations can arise where doctors get involved willy nilly. They may find themselves confronted with a prisoner whom they might help medically, and then it is difficult to draw the line between helping the prisoner and helping the regime. For example, if he is patched up, it may be only to be subjected to further torture. Downie misses this point when he says 'Of course, if it could be established that no one should ever be involved in torture then it would follow that doctors should not - the greater set would contain the lesser' (page 136). In a regime where torture is practised, a doctor might not be able to avoid being involved in various ways. But he will normally be able to control the extent and the kind of involvement. Doctors living under such regimes will be wise, therefore, to make for themselves some firm rules which they do not depart from, and if possible get them adopted by the governing bodies of their profession. What these rules should be needs further discussion, and has received it. They would probably include a rule no to treat torture victims until they are free, distastefux as this policy may be; for otherwise the doctor wi become an ancillary to further torture. And they wif certainly include a rule to give only such treatment as is for the good of the victim. However, those with practical experience are better able to suggest and assess such rules than I am.

The main point is that even a utilitarian like me (perhaps especially a utilitarian like me), if he thinks the matter through and looks at the consequences of the adoption or abandonment of such firm rules, will recommend that doctors find the best ones and stick to them. He should not be led astray by considering unusual examples in which involvement in torture in support of the regime might be for the best. Even if there are such cases, principles devised to suit them would not be appropriate to the normal case; and if we are to give ourselves the best chance of acting rightly in all normal cases, we had better have firm rules that suit those normal cases. Hard cases make bad law.

$R M$ Hare is Professor of Philosophy at the University of Florida, Gainesville, Florida, USA.

\section{References}

(1) Kant I. Groundwork of the metaphysic of morals, BA66 $=429$, in translation by Paton $\mathrm{H}$ J. The moral law. London: Hutchinson, 1948: 91.

(2) See reference (1): 92

(3) Kant I. Doctrine of virtue. A1 19=449, in translation by Gregor M. Philadelphia: University of Pennsylvania Press, 1964: 117. 
(4) Hare R M. Could Kant have been a utilitarian? Utilitas 1993; 5: 1-16.
(5) Hare R M. Freedom and reason. Oxford: Oxford University Press, 1963.

\section{News and notes}

\section{Call for papers}

The third annual meeting of the Association for Practical and Professional Ethics will be held 24-26 February, 1994, in Cleveland, Ohio. The hosts for the meeting will be Case Western Reserve University's Center for Biomedical Ethics and Center for Professional Ethics.
If you wish to submit a paper write to the Association for Practical and Professional Ethics, 410 North Park Avenue, Bloomington, IN 47405; or write via e-mail to APPE@INDIANA.BITNET or APPE@INDIANA. EDU (Internet); or call (812) 855-0261. 